Article

\title{
Applications of Location-Based Services and Mobile Technologies in K-12 Classrooms
}

\author{
Robert Kolvoord ${ }^{1, *}$ (D), Kathryn Keranen ${ }^{2}$ and Paul Rittenhouse ${ }^{2}$ \\ 1 Professor and Dean, College of Integrated Science and Engineering, James Madison University, \\ Harrisonburg, VA 22807, USA \\ 2 Lecturer, Integrated Science and Technology, James Madison University Harrisonburg, VA 22807, USA; \\ kkeranen@me.com (K.K.); rittensp@jmu.edu (P.R.) \\ * Correspondence: kolvoora@jmu.edu; Tel.: +1-540-568-2752
}

Academic Editors: Carlos Granel, Sven Casteleyn, Angela Schwering and Wolfgang Kainz Received: 2 May 2017; Accepted: 5 July 2017; Published: 8 July 2017

\begin{abstract}
The use of location-based services and mobile technologies is increasing in K-12 classrooms. In this article, we describe the history and the current use of these tools in the innovative Geospatial Semester project in Virginia. We share a number of examples where students are creating projects of their own interest that use editable feature services, mobile data collection and other cutting-edge technologies. These projects help students build their spatial thinking and problem-solving skills, and help teachers build conceptual understanding in a variety of domains.
\end{abstract}

Keywords: location-based services; K-12 education; geospatial technologies; spatial thinking

\section{Introduction}

The use of mobile applications and devices is reinventing the use of geospatial technologies at all levels from business and industry to the classroom. Students are now getting the opportunity to use mobile devices as a learning platform for a variety of subjects, especially geography, and to build their spatial thinking skills.

Spatial thinking skills are critical to success in Science, Technology, Engineering, and Mathematics (STEM) careers [1], yet there are few places in the K-12 curriculum where these skills are taught. Geospatial technologies in general, and mobile apps and location-based services (LBS) in particular are a great way to help build these critical skills.

In this paper, we will use a case history approach to describe a unique program in Virginia that provides opportunities for high school students to become deeply immersed in geospatial technologies and spatial thinking and problem-solving. This program, the Geospatial Semester (GSS) now features mobile technologies and location-based services (LBS) in students' coursework and projects. The use of these cutting-edge technologies has the potential to both motivate students and connect them even more strongly to the mobile-based world in which they live their lives. These student-created location-based services and novel applications of mobile technologies represent the first of what will likely be many instances of students taking ownership of these technologies to support their learning.

This case history starts with a section on the background of mobile technologies and LBS in education and the Geospatial Semester, followed by a description of the use of LBS in the Geospatial Semester over the last decade. We continue with a discussion of current and potential future uses of LBS and mobile technologies in the Geospatial Semester, and education more broadly, coupled with reflections by teachers and students. The final section includes discussion and conclusions. 


\section{Background}

Mobile technologies and LBS have a long history in education. From the very earliest days of commercial GPS, educators were looking for applications to help motivate their students. Place and location have always been critical concepts, even if Geography does not have a strong foothold in the K-12 curriculum in the United States.

The Clinton Administration's decision in 2000 to turn off Selective Availability [2] was a watershed moment in the use of global positioning system technology (GPS) in schools and more broadly across society. As the handheld GPS unit market blossomed, teachers were looking for ways to put this innovative technology into students' hands and help them learn about navigation and collect geo-referenced data [3]. Geocaching and Earthcaches (http:/ /www.geosociety.org/earthcache) have both been used in K-12 education [4], though little work has been done to investigate their efficacy.

More recently, schools have tapped into the citizen science movement, using applications designed by others to collect and analyze data [5]. Applications such as JourneyNorth (https://www.learner. org/jnorth/), LeafSnap [6] (http://leafsnap.com/) and oakmapper.org (http://oakmapper.org/) offer opportunities for students to participate in large-scale projects, however, the student participants have little to no impact on the design or ultimate analysis of the data; rather, they are just part of the larger data collection community. In fact, little attention has been paid to the use of mobile technologies and LBS in K-12 education, and no studies have been conducted on the creation of LBS by K-12 students.

Since 2005, the GSS has been helping high school seniors in Virginia stay motivated and engaged through their final year in secondary school $[7,8]$. GSS students take a semester- or year-long class that focuses on geospatial technologies and for which they can earn college credit from James Madison University. University faculty are regular visitors to the high school classes and help support teacher and students, as well as mentor the in-depth final projects required of all students. The next section details the history of mobile technologies and LBS in the GSS.

Recent research has shown that the GSS improves students' spatial thinking skills, as measured by their use of spatial language, and their improved problem-solving strategies $[9,10]$. We also have evidence to show that students' project work is of high quality and shows advanced levels of proficiency in 21st Century Thinking Skills [11].

\section{History of the Use of LBS in the Geospatial Semester}

Geospatial tools have advanced at a rapid rate since the founding of the GSS in 2005, particularly location-based tools used for data collection. In 2005, positions were collected by handheld GPS devices, with attributes often recorded on paper by hand. Any type of data collection that involved multiple users or multiple teams required substantial coordination to end up with consistent data. This improved slightly when the GPS-derived locations could be easily uploaded to a computer, but the attributes still had to be added manually. Particularly in a school environment, data validation and verification was a time-consuming and often frustrating challenge. In the following figures, we share three examples of student work showing the evolution in the use of LBS and mobile technologies over the last twelve years. Figure 1 shows an example of a student project where the data were collected with a handheld GPS unit, and attributes were manually entered. While the final result, a survey of potholes in an area of Northern Virginia, is substantial, there was a great deal of effort and some error in the data collection process.

Classroom access to advanced GPS receivers, such as the Trimble Juno series, allowed formatted attribute data entry. Figure 2 shows how students were able to inventory and map assets on a community farm and create an interactive map for visitors to explore on the farm's website. While this process improved data management issues, the advanced GPS units did have a more challenging learning curve and were not easily available for school use. 


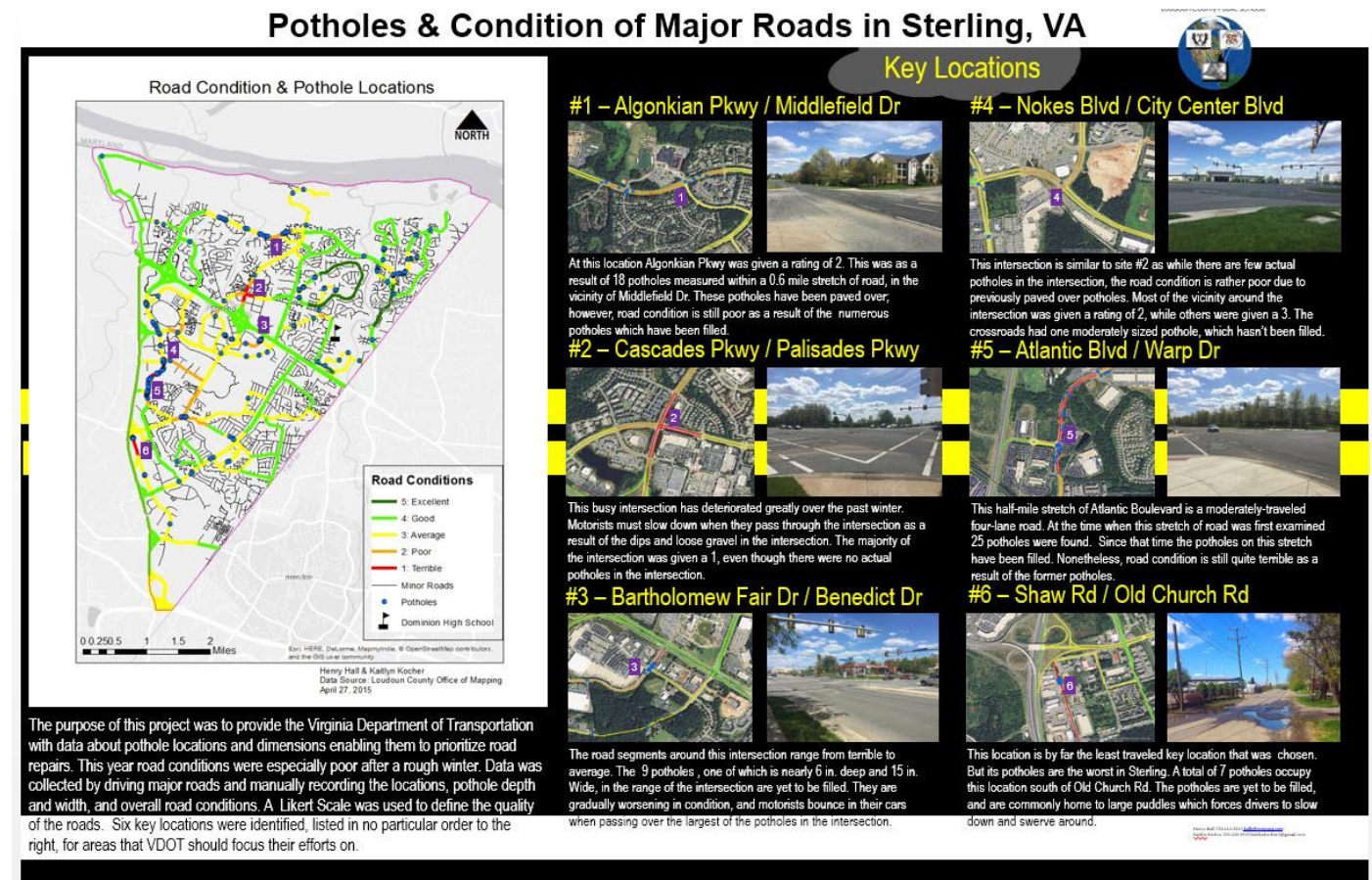

Figure 1. Student project with hand-entered GPS points and attributes.

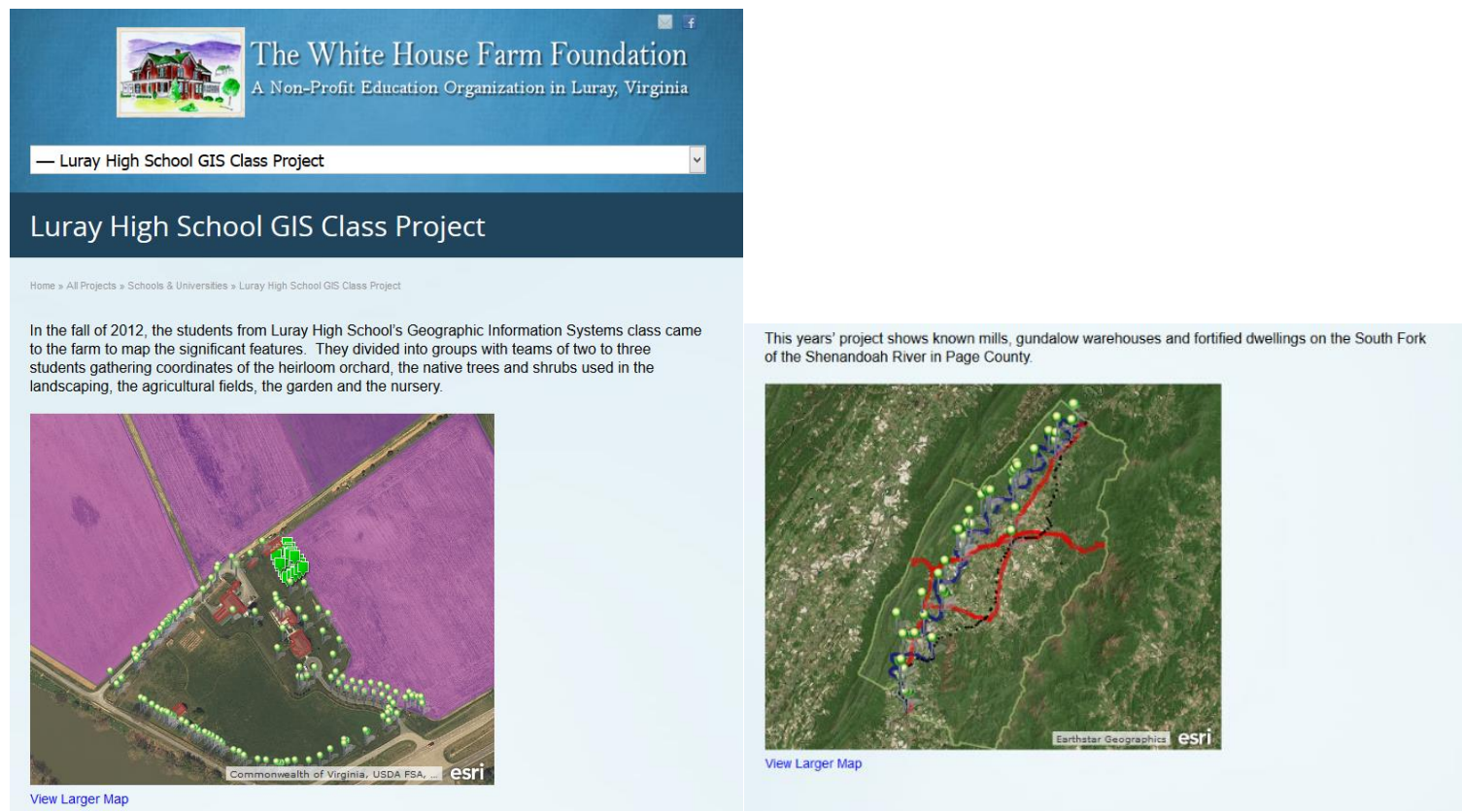

Figure 2. Student Project with Advanced GPS Unit (https:/ /whfarmfoundation.org/all-projects/ schools-universities/luray-high-school-gis-class-project/).

The development of cloud-based GIS has dramatically changed this landscape. Data can now be collected collaboratively on one map with almost no additional coordination. The creation of feature services now allows for consistent data collection with relatively little effort. In contrast with Figure 1, the data in Figure 3 were collected using a cloud-based editable feature service (EFS) that had a defined data dictionary. EFS allow the developer to constrain the choices for data entry, eliminating many of the data validation and verification issues that arose in the early days of GPS use in the classroom. This data collection process was considerably swifter and there were many fewer user errors in the 
data entry. These EFS and the ability to access them on browsers and apps on mobile devices provide considerable opportunities for the integration and use of LBS in a variety of curriculum-related projects in the $\mathrm{K} 12$ classroom.

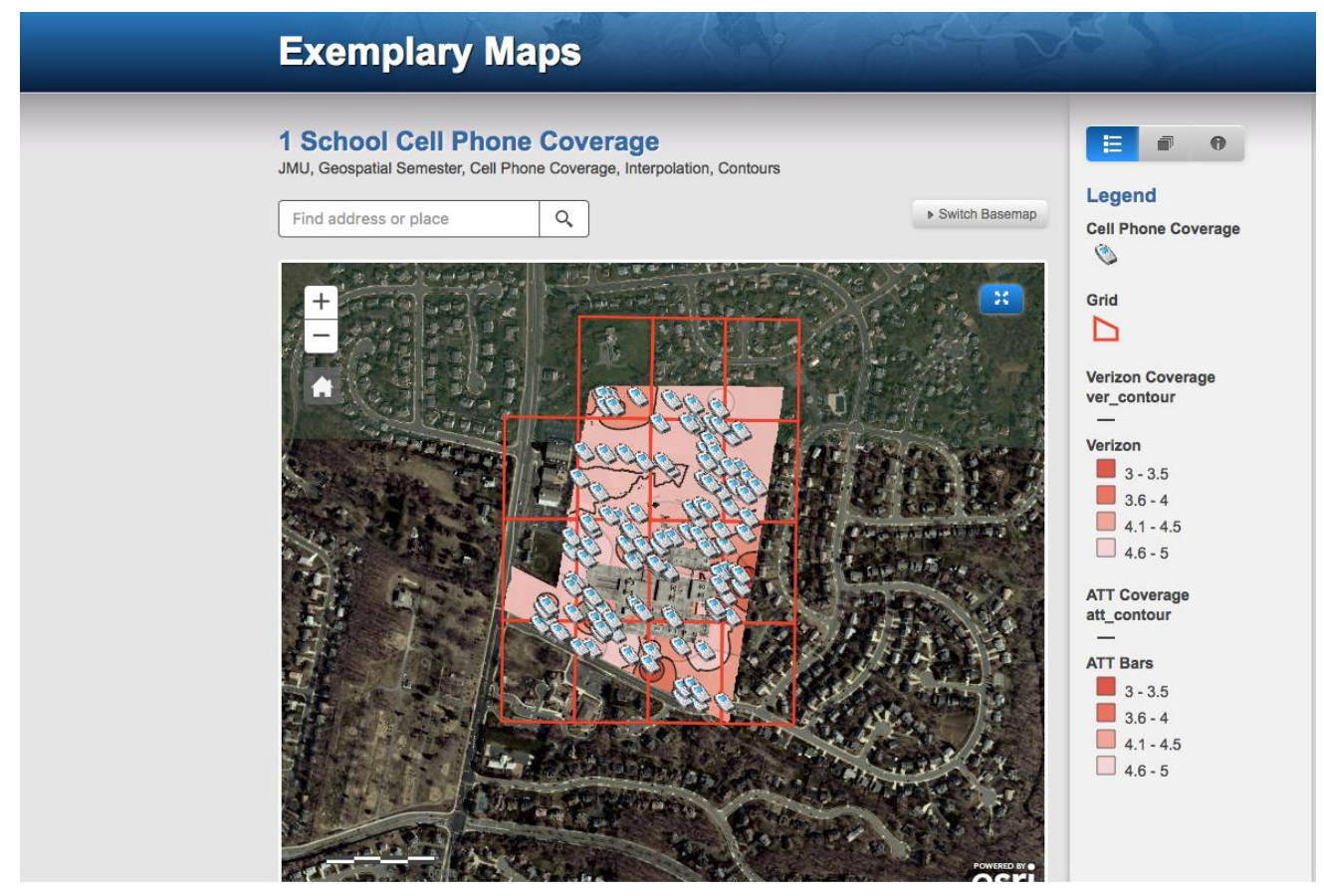

Figure 3. Cloud-based editable feature services (EFS) collected collaboratively to map campus cell phone coverage (http://kkoffice.maps.arcgis.com/apps/PublicGallery/map.html?appid= fdc75a0fc0e84a5b944f1b7fe96e0b2b\&webmap=2bc61e7249694f508aa5e1bdfd6283e5).

\section{Current and Future Uses of LBS in the Classroom}

The ability to collect data in a coordinated, systematic way through mobile apps both improves and increases the opportunities for students to gather authentic data in a variety of fields. Often these data have been difficult to collect due to limits in time, access to study areas, equipment issues or limited content knowledge. Now classrooms can navigate these hurdles by accessing carefully constructed EFS through the use of applications such as ESRI Collector [12], Survey 123 [13] apps or ESRI Geoforms [14].

While it may not have been previously feasible for one, or a group of students, to gather cell phone data (Figure 3) over a school campus during one class period, multiple groups can now spread out and gather data and populate the same EFS through the Collector App simulataneously.

Sometimes data collection needs to be more fluid and cannot be limited to one time, or one set of data collectors. Figure 4 shows portions of a student-designed EFS to be accessed through the ESRI Collector App that would allow personnel at an airport to track airplane bird strike data. The full student presentation can be accessed at the URL given in the figure caption. Regardless of the time of day, any personnel with the Collector app could record bird strike data in real-time. If the personnel do not have expertise in this area, the app helps ensure that the data entry protocol is followed correctly. Ultimately, this data can be accessed in desktop or online applications to be analyzed. 


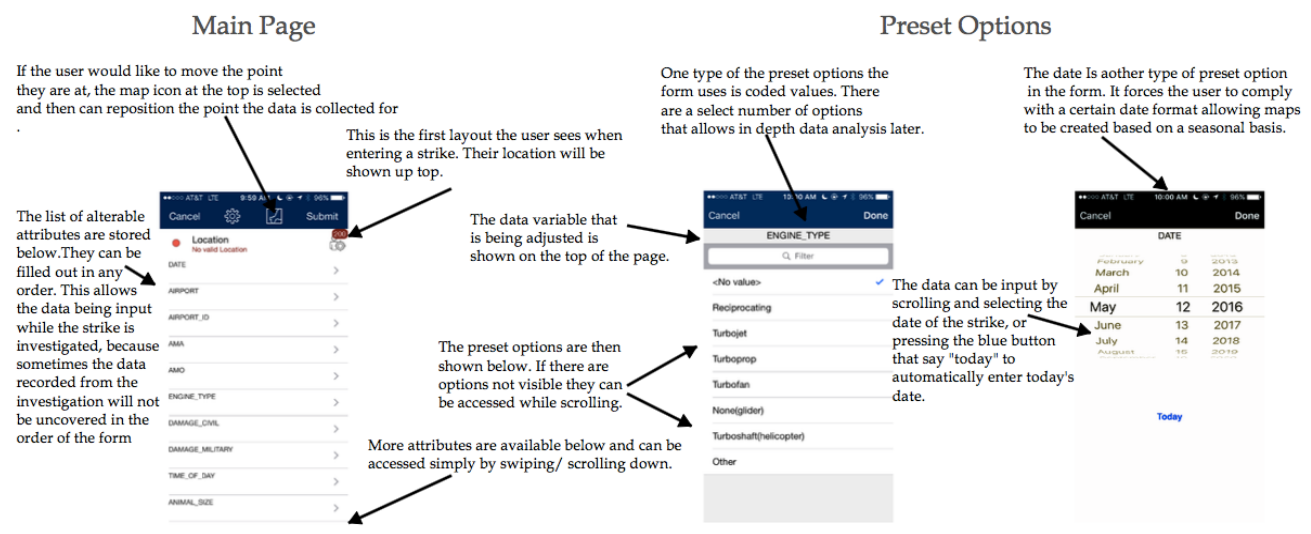

What Can This Do?
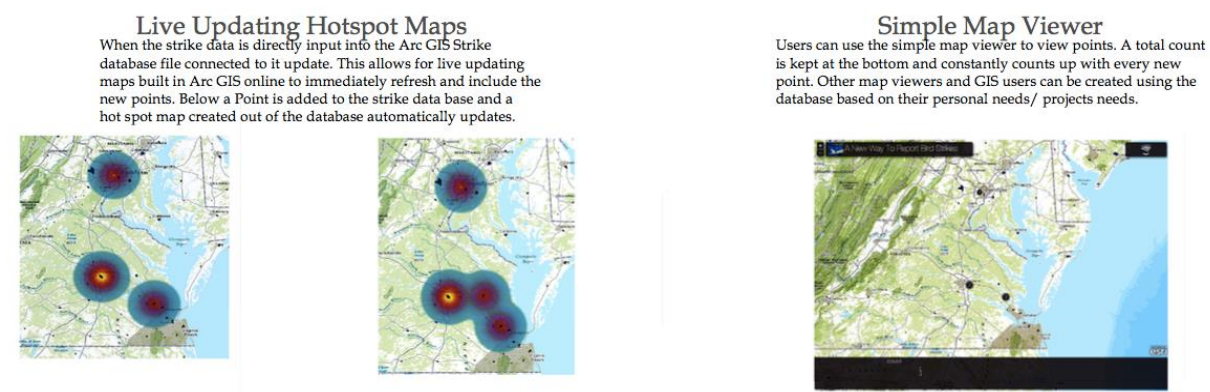

Figure 4. Bird Strike Collector Project Example (http:/ /www.isat.jmu.edu/geospatialsemester/1516winners/1_Collector_for_BirdStrikes.pdf).

If data collection needs to be expanded to a broader group, or crowdsourced to individuals who do not have a working knowledge of the ESRI Collector App, then GeoForms or Survey 123 Forms can be accessed via the web or the Survey 123 App on a desktop or mobile device. In these instances, the individual fills out a form with questions that include a geolocation. This geolocation is either derived from the mobile device or IP address or manually entered by means of an address, coordinates, or a click on a map.

This platform provides the means to capture a variety of data that are now spatially enabled. One school is currently designing a survey to determine where in the district students have access to broadband. In a service learning project, another school is working with its city and local officials to create public forms to report trail needs in a park (Figure 5), wild animal sightings (Figure 6), or city improvement needs (Figure 7). A noted benefit of Survey 123 is that it allows for conditional questions: the response to one question determines future questions presented on the form. In Figure 7 , a response asking for feedback on a report results in a prompt to provide an email address.

This ability to have conditional questions, along with integrating media, allows Survey 123 forms to be customized into quality guides. For example, students can design taxonomic keys for tree, plant, or bird identification. Media showing the differences in leaves or the songs of birds could help the user correctly identify species-resulting in spatial datasets that are increasingly more reliable.

The end product of data collected via LBS can in turn be shared back with specific groups or the public. Maps can be shared via ArcGIS Online (Figure 3) and interactive story maps can be published to create location-based guides. In Figure 8, data collected using LBS has been turned into a published interactive guide for individuals wanting to know more about hiking trails in Nelson County, Virginia. 


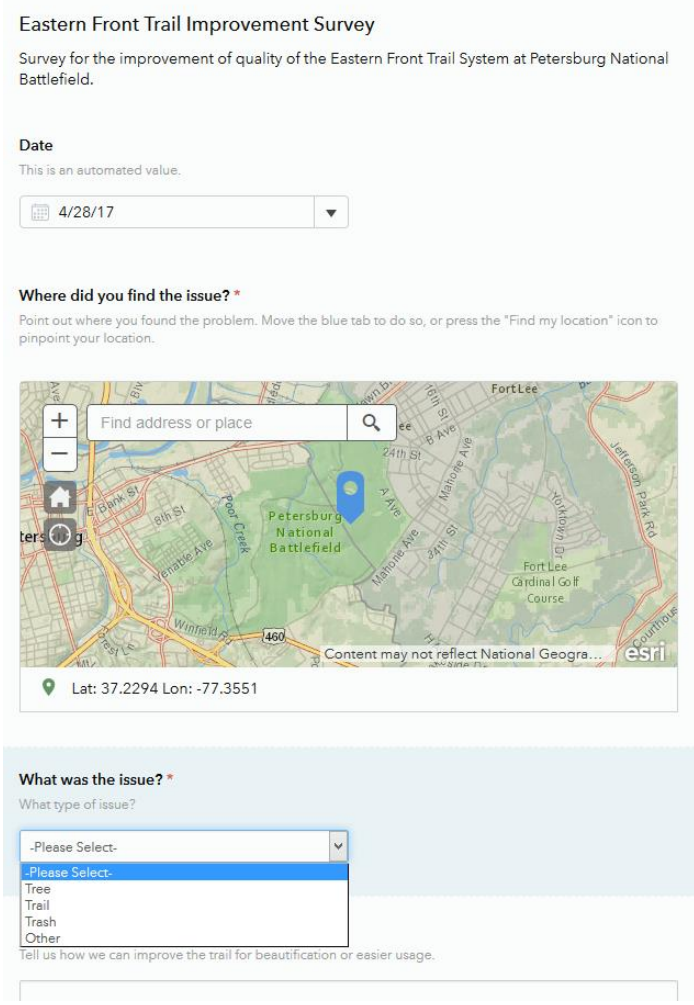

Figure 5. Eastern Front Trail Improvement Form (https://survey123.arcgis.com/share/ ae80624007cc4635a6e03c704ef0707a).

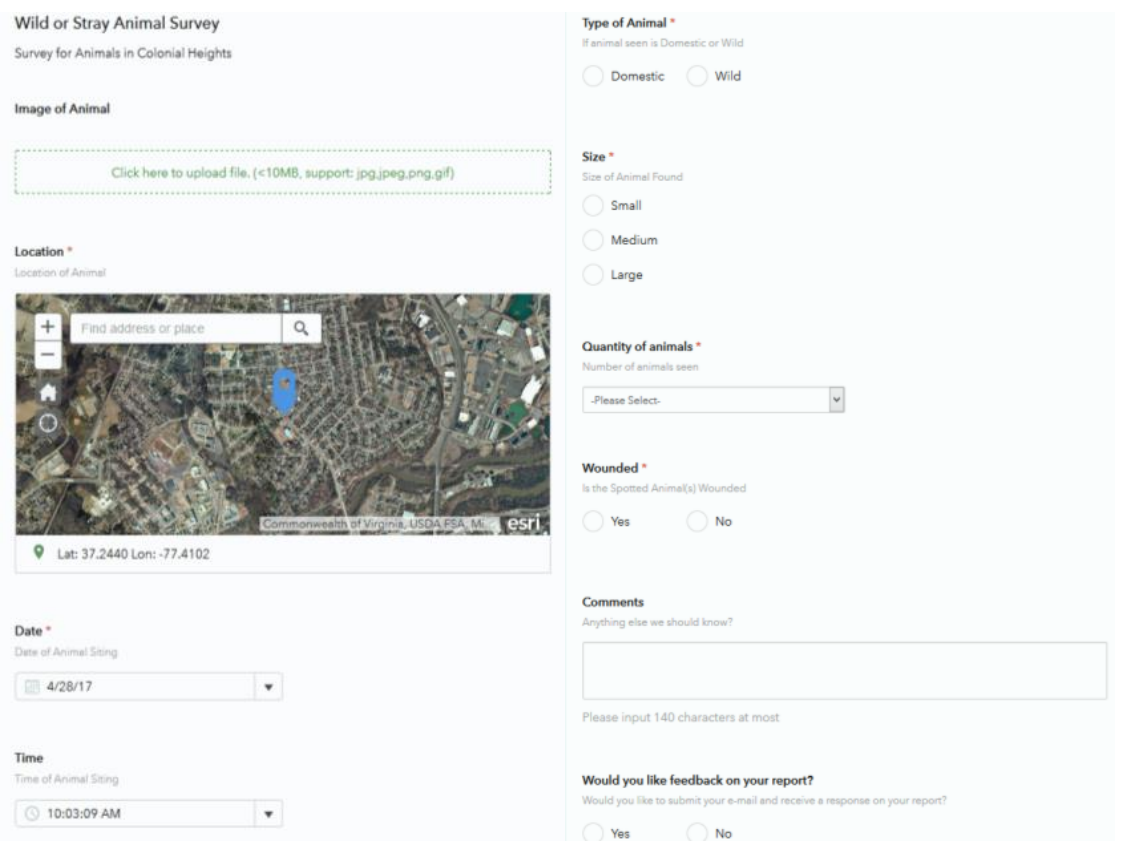

Figure 6. Wild Animal Report Form (https://goo.gl/2JhDZp).

Teachers and students have been strongly supportive of the addition of mobile and LBS into the GSS. In response to a set of questions asking about the impact of these technologies on their classes, teachers note that these technologies integrate well with the inquiry-based pedagogies that they use in their classrooms. One teacher said "the use of mobile technologies and LBS assists in my pedagogical 
mission ... They help to foster collaboration and can help train students in the use of technology that could work to further their career marketability." The issue of promoting possible careers was a prominent motivator for many GSS Teachers, especially given the growing importance of mobile and LBS technologies.
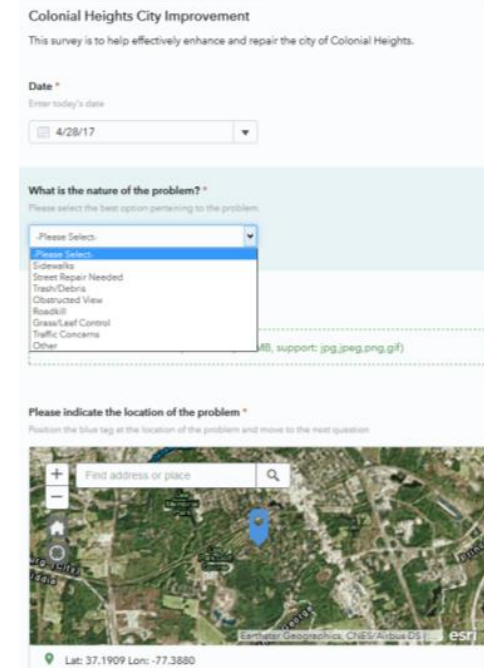
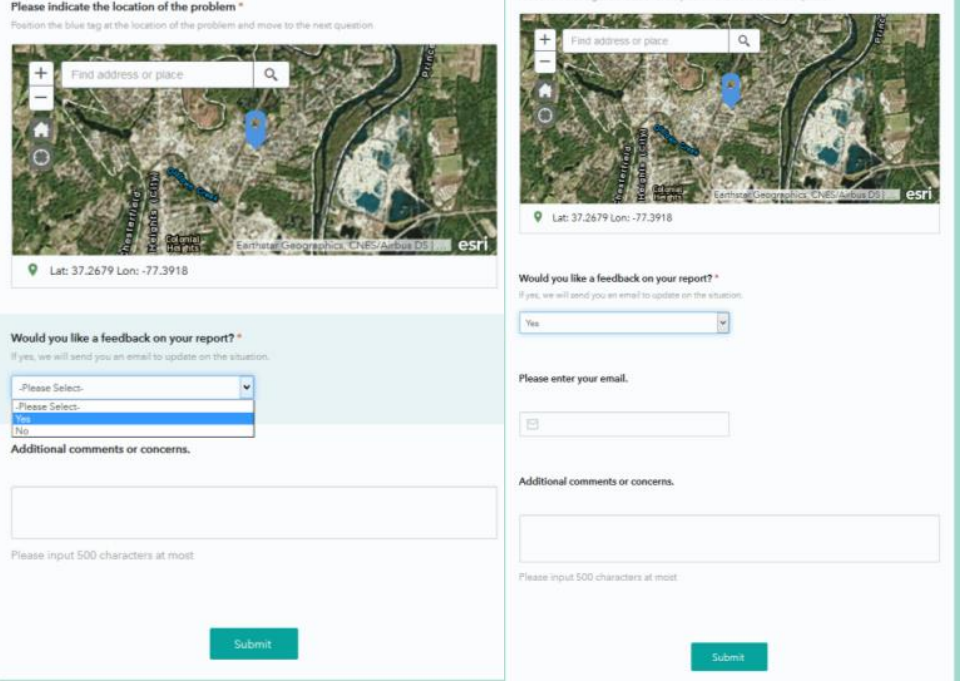

Figure 7. City Improvement Report Form (Three screens) (https://survey123.arcgis.com/share/ 5174bcc151d141b78ed442c58a4a0dff).

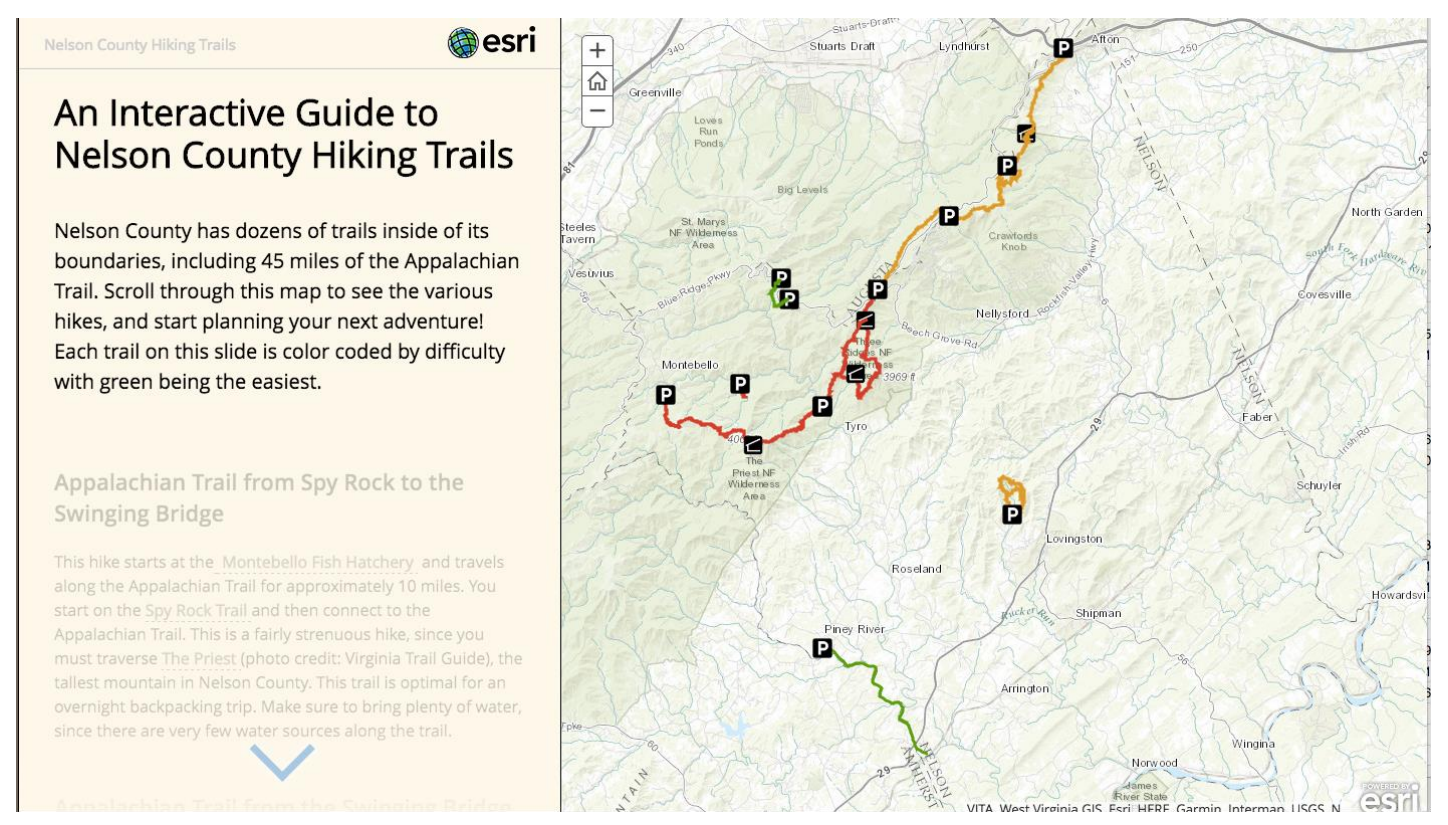

Figure 8. Interactive Guide to Nelson County Hiking Trails (https:/ / ncps-nms.maps.arcgis.com/apps / MapJournal/index.html?appid=1bc2c7a9b90242418e518c22bf32f43a).

Teachers also saw the value for students in using these tools to connect with broader communities and to tie their technology skills to benefit their local communities. One GSS teacher described this interaction as follows: "Students gain an understanding of concerns for their community and how they could help the city respond to citizen concerns in a timely manner." Another teacher stated mobile technologies and LBS "allow for an expanded repertoire of classroom activities and lessons that ultimately benefit the school and outside community at large. The students see these benefits and 
relish the notion that they too can benefit our various communities through their use of these devices and their actions." These comments were typical of teachers' reactions to the introduction of these technologies in their classrooms.

Students also saw considerable benefit to using mobile technologies and LBS. The technologies made the work of collecting and managing their data much simpler, in fact, one student noted "It was a stress reliever and made the process of collecting and importing data a lot easier." Other students noted the improvement in accessibility in both data collection and data access. Students also appreciated the opportunities for greater collaboration and real-time data creation. One student very eloquently reflected on this process: "With the ubiquity of mobile devices, mobile technology can be used to collect data from a wide variety of connected sources. In our specific project, mobile technology was key to "citizen science" and allowing for individuals to have access to GIS insights, as well as helping to create those insights themselves." Students also appreciated potential advantages in both career opportunities and further study given their experience with cutting-edge technologies. One student said "It (mobile technologies and LBS) has taught me technological skills that will be handy in my future career goals of public safety." Another student noted "A lot of people do not have the access of knowledge to this kind of technology. This opportunity will put me ahead of everyone who does not have this type of information." A student who is planning to major in civil engineering at university was searching to see if the institution offered a minor in GIS, noting "any knowledge I gain in this will blaze a trail for my future."

This final comment provides a thoughtful and reflective summary of the student experience and speaks to the potential of the use of mobile technologies and LBS in K-12 education: "Although it does not form the basis of my enjoyment of GIS, which I consider a possible career goal, mobile geospatial technologies have the potential to bring GIS to a much greater portion of the population than it's currently available to. In terms of environmental education and awareness, which is a possible future career path of mine, it helps me to understand the ease to which people can integrate their own knowledge and surroundings into something larger. This makes larger problems seems more relevant to their everyday lives, which is instrumental in helping to motivate them to learn."

We note that the comments above came from a set of teachers and students who chose to respond to a short open-ended survey. The respondents do not necessarily constitute a representative sample of GSS teachers and students.

\section{Discussion and Conclusions}

Clearly the evolution of LBS and the growing accessibility of mobile technologies have dramatically expanded the opportunities for K-12 students and teachers to use geospatial technologies. The range of problems captures student interest and allows teachers to introduce key concepts and content in their classes. With many schools moving to having students bring their own devices (BYOD), and with the growing focus on apps, accessibility is no longer an issue. Furthermore, teachers can much more easily design data collection activities that result in datasets that are quick to create and easy to analyze. The challenge of helping teachers conceptualize problems that take advantage of the affordances of these technologies remains. We have worked with GSS teachers to provide professional development and example activities that help them integrate LBS and mobile technologies. Ultimately, data collection is only the beginning and not the final step in the analysis and problem-solving process. It's critical to help teachers and students envision spatial questions and the analysis required to answer those questions.

An important element in the adoption of LBS and mobile technologies in the GSS is offering the students some choice in their use. By capturing student interest in problems that have meaning to them, as shown above, teachers can facilitate substantial student achievement and engagement.

An interesting trend is the disaggregation of spatial analysis tasks into apps, de-emphasizing large and sometimes cumbersome software into compact and easy to use packages. This reduces the barrier to entry for many teachers and will lead to increased use by students. It also simplifies 
professional development and technical support, which are oft-cited limitations in the classroom use of geospatial technologies [15].

LBS and mobile technologies have become dramatically simpler to create and use in recent years, opening up a range of classroom uses in a variety of contexts. The ease of use for both teachers and students has broadened the array of problems accessible for spatial problem solving. Teachers are able to help students collect and analyze their own data, promoting students' interest and focus. By engaging in more opportunities to learn and apply spatial analysis, students are able to build their spatial thinking skills, thus augmenting their ability to access STEM-related careers and to see the power of the application of LBS and mobile technologies in real-world problems.

Author Contributions: Robert Kolvoord conceived the organization of the article and all authors contributed to the writing and review of the manuscript.

Conflicts of Interest: The authors declare no conflict of interest.

\section{References}

1. Wai, J.; Lubinski, D.; Benbow, C.P.; Steiger, J.H. Accomplishment in science, technology, engineering, and mathematics (STEM) and its relation to STEM educational dose: A 25-year longitudinal study. J. Educ. Psychol. 2010, 102, 860-871. [CrossRef]

2. National Coordination Office for Space-Based Positioning, Navigation, and Timing (2017). Selective availability. Available online: http://www.gps.gov/systems/gps/modernization/sa/ (accessed on 28 February 2017).

3. Broda, H.W.; Baxter, R.E. Using GIS and GPS Technology as an Instructional Tool. Soc. Stud. 2003, 94, 158-160. [CrossRef]

4. Gochis, E.E.; Rose, W.I.; Klawiter, M.; Vye, E.C.; Engelmann, C.A. EarthCache as a Tool to Promote Earth Science in Public School Classrooms. Presented at the American Geophysical Union 2011 Fall Meeting, San Francisco, CA, USA, 5-9 December 2011. Abstract \#ED51A-0735.

5. Connors, J.P.; Lei, S.; Kelly, M. Citizen science in the age of neogeography: Utilizing volunteered geographic information for environmental monitoring. Ann. Assoc. Am. Geogr. 2012, 102, 1267-1289. [CrossRef]

6. Wyner, Y. Using local street trees to teach the concept of common ancestry. Sci. Scope 2016, 39, 1. [CrossRef]

7. Kolvoord, R.; Keranen, K. The Geospatial Semester. J. Geogr. 2017. Submitted.

8. Kolvoord, R.; Charles, M.; Meadow, N.; Uttal, D. The Impact of Geospatial Technologies in a Dual-Enrollment Environment. In Proceedings of the Society for Information Technology \& Teacher Education International Conference, Albuquerque, NM, USA, 5 March 2012; Resta, P., Ed.; pp. 1915-1922.

9. Jant, E.; Uttal, D.; Kolvoord, R. Defining and Measuring the Influences of GIS-Based Instruction on Students' STEM Reasoning. Ann. AAG 2017. Submitted.

10. Kolvoord, R.A.; Uttal, D.H.; Meadow, N.G. Using video case studies to assess the impact of the use of GIS on secondary students' spatial thinking skills. Procedia Soc. Behav. Sci. 2011, 21, 372-379. [CrossRef]

11. Charles, M.; Kolvoord, R.A. Geospatial Semester: Developing Students' 21st Century Thinking Skills with GIS: A Three Year Study. Pyrex J. Educ. Res. Rev. 2016, 2, 67-78.

12. Collector. Available online: http:/ /doc.arcgis.com/en/collector (accessed on 10 June 2017).

13. Survey 123. Available online: https:// survey123.arcgis.com/ (accessed on 10 June 2017).

14. ESRI GeoForms. Available online: https://www.arcgis.com/apps/GeoForm/index.html) (accessed on 10 June 2017).

15. Baker, T.R.; Palmer, A.M.; Kerski, J.J. A National Survey to Examine Teacher Professional Development and Implementation of Desktop GIS. J. Geogr. 2009, 108, 4-5. [CrossRef]

(C) 2017 by the authors. Licensee MDPI, Basel, Switzerland. This article is an open access article distributed under the terms and conditions of the Creative Commons Attribution (CC BY) license (http://creativecommons.org/licenses/by/4.0/). 